\title{
Derecho agrario, herencia y tierra en ejidos del Noroeste de México: un análisis sociocultural con perspectiva de género*
}

\author{
MAGDALENA LAGUNAS VÁZQUES, LUIS FELIPE BELTRÁN MORALES \\ Y ALFREDO ORTEGA RUBIO
}

\begin{abstract}
Mediante una caracterización, en términos socioculturales, de las mujeres ejidatarias en cuatro ejidos de Baja California Sur, se estudian sus procesos de acceso a la tierra y el derecho agrario, los principales patrones de herencia y las desigualdades de género en su entorno rural ejidal. Se utilizan entrevistas semiestructuradas, a profundidad y diario de campo con perspectiva de género. El porcentaje de mujeres con derechos agrarios es mínimo y 90\% los adquirió por herencia. Más de la mitad considera que existe discriminación hacia las mujeres. Los patrones culturales de acceso a la tierra, las costumbres sobre la herencia, y en general, el papel de la mujer campesina en la sociedad propician la situación de desigualdad de género que prevalece en el campo.
\end{abstract}

PALABRAS CLAVE: ejidos, perspectiva de género, desigualdad agraria, mujeres campesinas, ejidatarias

Land Rights, Inheritance and Land in Ejidos of Northwest Mexico: A Sociocultural Analysis with Gender Perspective

MAgdalena Lagunas VÁZQueS Centro del Cambio Global y la Sustentabilidad, Villahermosa, Tabasco, México vaz.lag@gmail.com

LUIS FELIPE Beltrán MORALes

Centro de Investigaciones Biológicas del Noroeste, La Paz, Baja California Sur, México Ibeltran04@cibnor.mx

\section{AlFredo Ortega RuBio}

Centro de Investigaciones Biológicas del Noroeste, La Paz, Baja California Sur, México aortega@cibnor.mx
We aim to describe women ejidatarias socioculturally in four ejidos - village communal holdings - of Baja California Sur, including their processes of access to land and agrarian rights, the main patterns of inheritance and gender inequalities in a rural environment. Semi-structured and in-depth interviews, and field diaries with a gender perspective are used on methodological approach. The percentage of women with land rights is minimal and $90 \%$ acquired them by inheritance. More than half believe that there is discrimination against women. Cultural patterns of access to land, customs over inheritance, and in general the role of peasant women in society propitiate the situation of inequality currently prevailing in the countryside for rural women.

KEYWORDS: ejidos - village communal holdings-, gender perspective, agrarian inequality, rural women, women with land rights 


\section{Introducción}

os objetivos del presente trabajo son identificar y caracterizar socioculturalmente a las mujeres ejidatarias en cuatro ejidos de Baja California Sur (BCS), reconocer y definir los patrones y procesos de acceso a la tierra y el derecho agrario de las ejidatarias, y registrar su percepción de la discriminación y las desigualdades de género en su entorno rural ejidal, así como su participación en cargos públicos. El estudio se realizó en cuatro ejidos de BCs: Alfredo V. Bonfil, municipio de Mulegé; El Centenario, Chametla y Alfredo V. Bonfil, municipio de La Paz. Los datos sobre las ejidatarias se obtuvieron del Registro Agrario Nacional (RAN) en línea. Se identificaron 91 mujeres en el padrón de sujetos agrarios. Durante febrero y marzo, y junio y julio de 2016, se visitaron las comunidades o núcleos poblacionales de los ejidos; se hicieron 31 entrevistas semiestructuradas, siete a profundidad con ejidatarias, y se tomaron notas de campo.

El contenido de este artículo contempla los siguientes apartados: 1) introducción general sobre el estudio para presentar los objetivos y cómo y dónde se hizo el estudio, entre otros aspectos; 2) antecedentes; revisión breve sobre la historia agraria de Latinoamérica para describir los principales procesos de reparto agrario en la región y la situación de la mujer en este proceso, el derecho agrario y la tenencia de la tierra de las mujeres, y una breve historia de la reforma agraria mexicana; 3) información metodológica sobre cómo se identificaron las ejidatarias; la

* $\quad$ Agradecemos profunda y sinceramente a todas las ejidatarias, posesionarias y avecindadas de los cuatro ejidos, que nos otorgaron su tiempo y sus palabras, en especial a Trinidad Valdez, Rosario Vázquez, Magdalena Camarillo, Elsa Martínez y Lourdes González. También se agradece el apoyo de Deysi Guadalupe Jerónimo Mendoza y Miguel Ángel Salinas Beltrán en el trabajo de campo. Este artículo forma parte de las actividades de la Red Nacional de Áreas Naturales Protegidas (Renanp) del Consejo Nacional de Ciencia y Tecnología (Conacyt), proyecto 293368, y del proyecto Conacyt 251919 de Ciencia Básica. 
estrategia en campo, herramientas y principales preguntas que guiaron el análisis; 4) resultados; caracterización socioambiental de los ejidos en estudio; distribución de los sujetos agrarios en los cuatro ejidos estudiados; caracterización sociocultural de las mujeres ejidatarias, patrones y procesos de acceso a la tierra y el derecho agrario de las ejidatarias; preferencias de herencia del derecho ejidal de las ejidatarias; percepción sobre discriminación ejidal; participación política de las mujeres ejidatarias en el entorno ejidal, y 5) conclusiones; con una serie de recomendaciones para la formulación de política pública, que surgen del análisis de la situación estudiada en su contexto, con el fin de aportar a la igualdad y equidad en cuanto a la propiedad y derecho agrario para las mujeres campesinas.

\section{Antecedentes}

\section{BREVE HISTORIA DE LA REFORMA AGRARIA EN LATINOAMÉRICA}

La experiencia de la reforma agraria (RA) en Latinoamérica permite formular una conclusión general: con independencia del alcance de la reforma, las mujeres del sector rural, en gran parte debido a una legislación neutra, fueron excluidas como beneficiarias directas (Deere y León, 2001). Quienes planearon las reformas agrarias tenían la intención de beneficiar a las familias campesinas, pero al suponer que los procesos eran neutros respecto al género, éstos terminaron sesgándose y favorecieron sobre todo a los hogares con jefatura masculina (Deere y León, 2004).

En Latinoamérica -excepto México, que emprende la RA a principios del siglo pasado-, los primeros años de la reforma fueron entre 1970 y 1980. En el reparto de tierra se observa que, en promedio, las mujeres representaban $11 \%$ de los beneficiados
(León, 2006), porcentaje devenido de los procesos de RA. De acuerdo con diversos estudios, a las mujeres se les excluyó de las reformas agrarias latinoamericanas por razones legales, estructurales, ideológicas, culturales e institucionales (León, 2006). Casi todas las leyes de RA en la región parecen neutras en cuanto al género (Facio, 2002; León, 2006).

Se considera que existen dos conceptos con carga cultural que impregnaron las reformas agrarias latinoamericanas: el de agricultor y el de jefe del hogar. En Latinoamérica, la agricultura ha sido interpretada en términos sociales como una ocupación masculina (Deer y León, 2004). Como expone Córdova (2003), entre diversos autores, la tierra es a la vez signo y referente de un conjunto de nexos sociales que involucra pertenencia y lugar en una sociedad; su posesión puede implicar prestigio y poder sobre otros, y su carencia puede representar sujeción y vulnerabilidad.

Los avances en la paridad de la titularidad de la tierra y reformas agrarias con igualdad de género en Latinoamérica ofrecen este panorama durante la primera década del siglo xxi: en 2001, Venezuela implementa un lenguaje inclusivo en su nueva ley de tierras y desarrollo agrario (Chávez, 2001), que establece que las mujeres jefas del hogar deberían ser los "sujetos beneficiarios preferenciales de adjudicación" (Deere, 2012). Bolivia y Ecuador también adoptaron nuevas constituciones en las que se estableció la obligación del Estado de eliminar la discriminación contra la mujer en el acceso a la tierra. En Brasil, para 2007, las mujeres eran titulares de 31.5\% de las tenencias. En Bolivia, el ritmo de redistribución de la tierra se incrementó de 2006 a 2010, pues los hombres representaban $37.2 \%$ y las mujeres 24.1\%, el resto era de titulaciones conjuntas. En la última década, Bolivia, Ecuador, Venezuela y Brasil todavía están en proceso de distribución de tierra (Deere, 2012).

También se han hecho modificaciones a leyes agrarias con base en políticas más igualitarias 
y equitativas - por ejemplo, en Honduras, Nicaragua, Bolivia y Colombia, entre otros países-, en las que se estipula que el título de tierra debe ser obligatorio para el hombre y la mujer que forman una pareja, con lo que se reconoce la doble jefatura del hogar y el derecho a administrar el patrimonio familiar en conjunto (Deere y León, 2001; León, 2006).

Entre los grupos y movimientos sociales que han aportado para la equidad de género en la titularidad de la tierra en Latinoamérica, se encuentran las siguientes organizaciones: Confederación Nacional de Mujeres Campesinas Indígenas Originarias de Bolivia "Bartolina Sisa"; Movimiento Sin Tierra; Coordinadora Campesina de Mujeres del Trópico de Cochabamba (Cocamtrop) —las mujeres cocaleras del Chapare-, y dentro del partido gobernante, el Movimiento al Socialismo (MAS) y la Vía Campesina, como movimiento aglutinador internacional que une pequeños productores alrededor del mundo y ha incorporado la perspectiva de género en su campaña global para la reforma agraria (Deere, 2012).

\section{BREVE HISTORIA AGRARIA EN MÉXICO}

El nuevo régimen de propiedad posrevolucionario mexicano fue una fusión de ideas y necesidades políticas que estableció limitaciones de orden público y social a la propiedad en general. La reforma agraria se implementa a partir de 1916 y 1917, y el ejido surge como una entidad que permite el reparto agrario mexicano (Warman, 2003). El reparto se estructura en la reforma agraria - en sus diversas modalidades, hasta su cuasi desaparición actual-, el artículo 27 constitucional y las legislaciones agrarias existentes (Warman, 1978; 1996). El ejido mexicano, como concepto, existe desde hace un centenar de años, atraviesa casi 50\% de la extensión territorial de la nación — si se incluyen los tipos de propiedad social existentes - e involucra a varios millones de habitantes (Warman, 1978; 1985).

El artículo 27 constitucional estipulaba "dotar de tierras y aguas suficientes" a la población rural; sin embargo, la reforma al artículo, en 1992, básicamente termina con el reparto agrario y propone otras condiciones, entre las más sobresalientes, la autorización para trasferir, vender y enajenar la propiedad ejidal, que antes era intransferible e inalienable, al otorgar títulos de propiedad e incluir otras categorías de sujetos agrarios en el ámbito ejidal (Warman, 1996). Esto dio pie a la privatización de la tierra, que antes era de propiedad social.

La primera ley agraria que se implementó en México, en enero de 1915 (Vizcarra, 2001), utilizó el modelo de familia patriarcal al considerar como norma que las unidades domésticas estaban encabezadas por un hombre y suponer que el derecho que se le otorga al padre de familia equivale al de toda la unidad doméstica (Vázquez, 2001). Tuvieron que pasar poco más de cinco décadas, de 1915 a 1971, para que la ley agraria indicara de manera textual que las mujeres podían participar como ejidatarias, y por ende, tener representatividad política dentro del ejido (Vázquez, 2001). Sin embargo, prevalece "la fuerza de la costumbre" —en palabras de Vázquez (2001) - , que hace que la herencia siga siendo la forma más dominante de acceso a la tierra para las mujeres, no las indicaciones en las legislaciones ni las estructuras jurídicas.

En México, el RAN es el gran archivo que incluye los padrones de sujetos agrarios a lo largo y ancho del país. Es un órgano desconcentrado de la antigua Secretaría de la Reforma Agraria, hoy Secretaría de Desarrollo Agrario, Territorial y Urbano (Sedatu), creado para el control de la tenencia de la tierra de carácter social y la seguridad documental. Es el respaldo documental de la propiedad de las tierras sociales en México (Gallart et al., 1999).

La principal categoría de sujeto agrario corresponde al de ejidatario, el cual posee un derecho 
agrario. Otras categorías de sujeto agrario son posesionario y avecindado dentro de un ejido, que se incluyen a partir de la modificación de la Ley Agraria en 1992 (SRA, 1992), vigente en 2016. Todas estas categorías permiten a una persona ser dueña de un título de propiedad o tenencia de la tierra, pero las avencindadas, en general, sólo poseen certificados de titulación del solar. Al poseer un derecho agrario y títulos de propiedad parcelaria, las ejidatarias tienen garantías usufructuarias de tierras y recursos ejidales de acuerdo con las leyes agrarias y de desarrollo rural, por eso una mujer campesina con un derecho agrario puede ostentar mayor poder de agencia y control efectivo de la tierra, así como participación con voz y voto en las decisiones que se tomen respecto a los recursos ejidales.

A continuación, se describe la evolución de los derechos agrarios y de propiedad de la tierra de las mujeres rurales en México, dentro del marco ejidal. México fue el primer país de Latinoamérica en establecer la igualdad jurídica formal entre hombres y mujeres en su legislación agraria, en 1971. Sin embargo, la regulación estipulaba que cada familia podía ser representada por un solo miembro, que por tradición era el jefe del hogar, un varón, es decir, en términos jurídicos, las mujeres no adquirieron derechos agrarios (Deer y León, 2002).

Este tipo de procesos de reformas, tanto a las leyes agrarias como a las estructuras estatales, no se sucedieron por cuenta propia ni de manera consecutiva; hubo un entramado de organización y lucha campesina femenina. Grupos de mujeres organizadas demandaron cambios a esta disposición jurídica agraria, existente durante el gobierno de Lázaro Cárdenas. Sin embargo, no lograron el reconocimiento de sus derechos sino hasta 1971, con las modificaciones de ley que otorgan los mismos derechos agrarios a hombres y mujeres. En esos tiempos, México se preparaba para recibir a las delegadas de la Primera Conferencia de la Mujer, convocada por la Organización de las Naciones Unidas, en 1975 (Vázquez, 2001).
A la par de la lucha por la tierra, se ha pugnado por los derechos de la mujer indígena. Sobre todo en las reuniones de Chiapas, las mujeres indígenas han planteado demandas concretas respecto a los derechos a la tierra. El Ejército Zapatista de Liberación Nacional (EZLN) fue el primer movimiento indígena en apoyar la demanda de derechos efectivos de la mujer a la tierra (Rojas, 1995).

Estudios profundos en la región chiapaneca describen que la participación de las mujeres ocurre en el ámbito agrario, principalmente como campesinas, incluso antes de reivindicarse como indígenas, y es justo en el medio agrario y la militancia, entre las décadas de 1970 y 1980, cuando las mujeres indígenas chiapanecas encuentran y generan espacios de participación y reflexión grupal (Castillo, 2001; Pérez, 2004).

El ámbito agrario en Chiapas fue y es un campo propicio en el que la población indígena, en particular las comunidades zapatistas organizadas, reinterpreta y reconstruye sus historias de manera constante, en especial en lo relacionado con la autonomía y el territorio, pues una de las pretensiones de la Revolución mexicana fue disminuir la identidad indígena y sustituirla por una identidad campesina priísta (Speed, 2004).

En Chiapas, grupos étnicos organizados se reunieron en un primer Congreso Indígena, en 1974 (Castillo, 2001). En este contexto nacional, regional, étnico-racial y sexogenérico desigual, las mujeres indígenas mexicanas que participaban en proyectos autonómicos reivindicaron su acceso a la tierra y los recursos comunitarios.

A pesar de la lucha y las exigencias para la adjudicación de la tierra a la mujer campesina, más de $60 \%$ de las mujeres que adquiere tierra dentro del ejido lo hace por herencia y más de la mitad de estos casos sucede a la muerte del marido (Reyes, 2006). En este contexto histórico y social sobre las mujeres con derechos agrarios en México, el porcentaje de mujeres propietarias es mínimo (véase 
CUADRO 1. PORCENTAJE DE HOMBRES Y MUJERES CON DERECHOS AGRARIOS DE 1970 A 2011 EN LOS EJIDOS DE MÉXICO

\begin{tabular}{cccc} 
Año & Hombres & Mujeres & Total \\
\hline 1970 & 98.7 & 1.3 & 100 \\
\hline 1984 & 85.0 & 15.0 & 100 \\
\hline 1988 & 82.4 & 17.6 & 100 \\
\hline 2007 & 76.6 & 20.4 & 100 \\
\hline 2011 & 79.0 & 21.0 & 100 \\
\hline
\end{tabular}

Fuente: Elaboración propia, con base en León (2006); INEGI (2007); Almeida (2009); PA (2011).

el cuadro 1). El mayor incremento tuvo lugar de 1970 a 1985. Una razón — documentada en otros estudios - podría ser la muerte de las primeras generaciones de ejidatarios, tras lo cual, las viudas sucesoras o herederas habrían tomado sus lugares, es decir, no eran beneficiarias directas sino colaterales (Deer y León, 2002; León, 2006; Reyes, 2006). Lamentablemente, las cifras del cuadro 1 no contemplan la propiedad ni el acceso a las tierras comunales de las mujeres indígenas mexicanas que pertenecen a una comunidad designada como agraria o tierras comunales, según la Ley Agraria vigente. Los datos oficiales sólo permiten hacer un análisis general del tema ejidal relacionado con las mujeres campesinas.

\section{Metodología}

Se desarrolló un análisis sociocultural que identifica y caracteriza a las mujeres ejidatarias en cuatro ejidos de BCS y se definieron los patrones y procesos de acceso a la tierra y el derecho agrario, así como las desigualdades de género en un entorno rural ejidal. Las preguntas que guiaron el análisis fueron:
- ¿Cuántas mujeres están dentro del universo de sujetos agrarios de los ejidos en estudio?

- ¿Cuáles han sido los procesos y patrones de acceso a la tierra y al derecho ejidal femenino en los ejidos en estudio?

- ¿Cuáles son los aspectos sociales y personales que caracterizan a estas mujeres ejidatarias, en términos de edad, promedio de hijos, alfabetización, escolaridad, estado civil y parentesco ejidal?

- Sobre las preferencias de herencia del derecho ejidal de las ejidatarias, se preguntó a las entrevistadas: ¿a quién heredaría su derecho ejidal: a un hijo o a una hija? ¿Cuáles son las razones de su decisión?

- Acerca de la percepción sobre discriminación ejidal, se preguntó: ¿ha sentido algún tipo de discriminación por ser mujer dentro del ámbito ejidal?

- ¿Cuál y cómo ha sido su participación política dentro del ejido?

Los datos se obtuvieron en el RAN. Sin embargo, la información disponible en línea quizá no esté actualizada, pues el padrón de sujetos agrarios de cada ejido es muy dinámico y cambia de manera constante. 


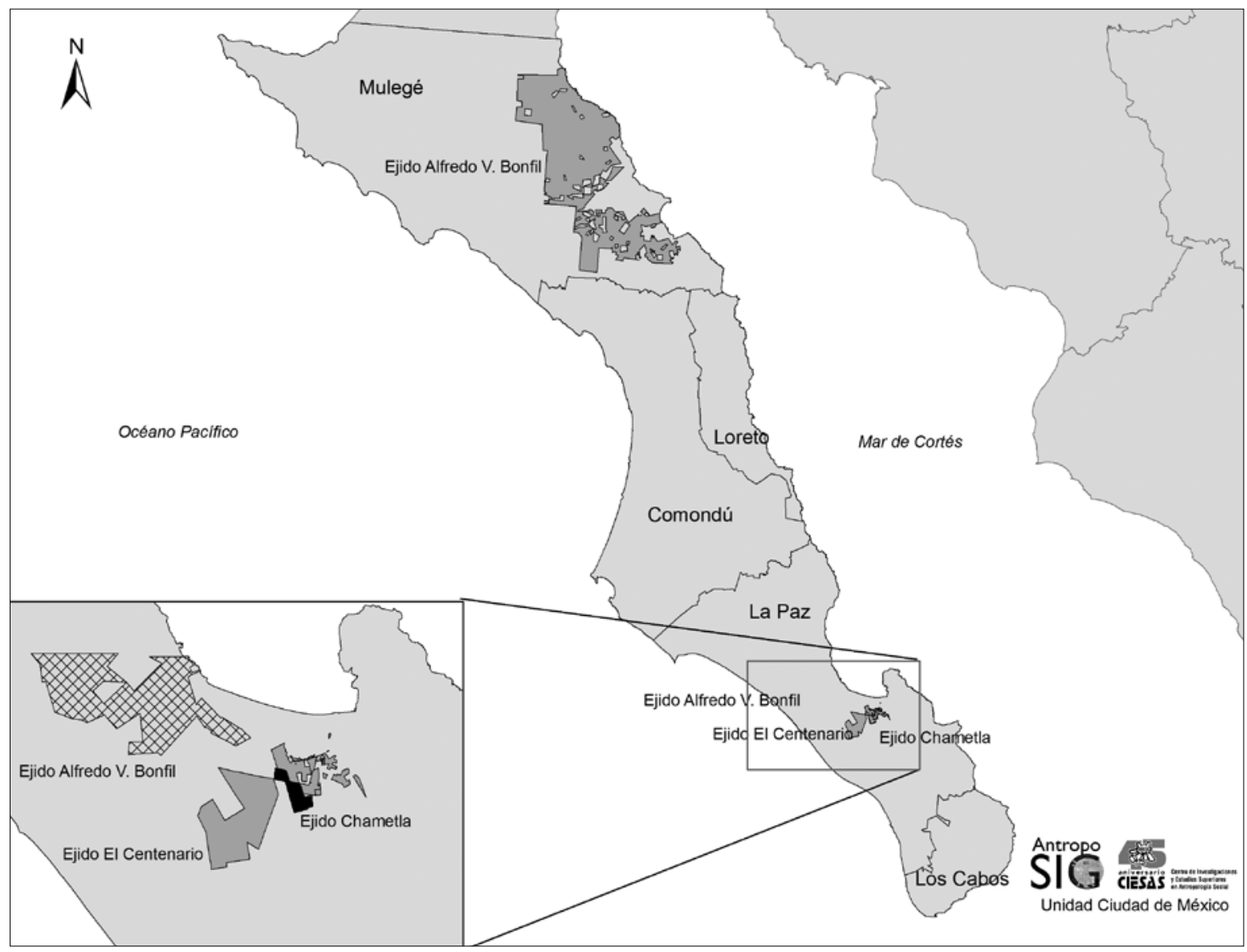

Elaborado por Bulmaro Sánchez Sandoval, con base en INEGI (2011: 14).

Además, en muchos ejidos un sujeto agrario ostenta más de un derecho ejidal o más de una categoría de sujeto agrario, por ello los datos en línea del padrón de sujetos agrarios para un ejido pueden diferir de los del ejido como tal. Para fines del presente estudio, se consideraron los números totales que ofrece el RAN, sin identificarlos de manera personalizada, de ahí que la cantidad de sujetos agrarios puede ser diferente de la que considera el ejido respectivo. Las principales herramientas metodológicas fueron la investigación de corte cualitativo, con entrevistas semiestructuradas, a profundidad y diario de campo con perspectiva de género.

En las ciencias sociales, se denomina género a la construcción simbólica en la que cada sexo representa su papel dentro de una cultura. Esta construcción reglamenta y condiciona la conducta objetiva y subjetiva de las personas, lo que es "propio" de cada sexo, socialmente esperado y aceptado (Lamas, 1996). La perspectiva de género implica distinguir entre la diferencia sexual y las atribuciones, ideas, representaciones y prescripciones 
sociales que se construyen con referencia a esa diferencia sexual.

El género afecta tanto a hombres como a mujeres. La definición de feminidad se hace en contraste con la de masculinidad, por lo tanto, género se refiere a las áreas estructurales e ideológicas que comprenden las relaciones entre los sexos (Lamas, 1996).

Las condicionantes culturales, económicas y sociopolíticas favorecen la discriminación femenina ( $\mathrm{La}-$ mas, 1996). La distribución no equitativa de bienes y derechos, el maltrato y la discriminación hacia un género en comparación con el otro no obedecen a una predisposición biológica, sino a una rotunda negligencia humana y social, que la cultura asigna y transmite por medio de significados, reglas, características, conductas, expectativas y valores, expresados en complejas interacciones institucionales, económicas, políticas, religiosas, etcétera (Rocha y Díaz, 2011).

De acuerdo con Vizcarra (2001), la mayoría de los estudios agrarios en México ha omitido el análisis de la condición de las mujeres del campo. Esta omisión puede atribuirse a que lo desarrollado en el campo mexicano durante la implementación de la reforma agraria era la legitimación de un poder y prestigio local en una sola dirección, un proceso de democracia patriarcal entre la población masculina del campo (Vizcarra, 2001), que resaltaba la idea del "buen patriarca": la representación de nociones de justicia, reciprocidad y responsabilidad familiar, para conformar una división socialmente correcta en el imaginario cultural (Deere, 1986).

Deere (1986), Vizcarra (2001), León (2006; 2011) y Cuaquentzi (2007) coinciden en que la agricultura se ha considerado una actividad masculina, en términos ideológicos y culturales, por lo que se da preferencia a este sexo en la posesión, usufructo y herencia de la tierra. El hombre también es privilegiado en el matrimonio, así como en programas comunitarios y del Estado sobre reparto de tierras, acceso y distribución de recursos, y apoyos para desarrollarse en el agro (Cuaquentzi, 2007).
Por todo lo anterior, se identificaron sólo 91 ejidatarias en el padrón en línea de sujetos agrarios del RAN, en relación con los ejidos estudiados (véase el mapa 1). Se hicieron nueve entrevistas en el ejido Bonfil, del municipio de Mulegé; 14 en el ejido El Centenario, siete en el ejido Chametla y una en el ejido Bonfil, del municipio de La Paz.

Mulegé es el municipio más norteño del estado. La Paz es el penúltimo municipio más al sur e incluye la ciudad capital que lleva el mismo nombre. En los últimos tiempos, el conglomerado urbano ha acaparado terrenos ejidales de El Centenario y Chametla, incluso sus propios núcleos ejidales son ahora colonias conurbadas de la capital, a unos $15 \mathrm{~km}$ de distancia.

\section{Descripción socioambiental de los ejidos}

Estos cuatro ejidos son una muestra representativa del entorno rural ejidal de BCS, se ubican en diferentes puntos del estado y poseen historias de conformación y constitución diversas.

\section{EJIDO ALFREDO V. BONFIL, MULEGÉ}

El ejido Bonfil tiene una superficie total de 504819.322511 ha, de las cuales 31100.911631 ha están parceladas. Los asentamientos humanos ocupan 71.656296 ha, se consideran 68.234992 ha como superficie reservada para crecimiento y 483334.588190 ha como de uso común. Es uno de los ejidos de mayor extensión territorial en el país. Casi 50\% está dentro de la Reserva de la Biosfera El Vizcaíno.

La fecha de resolución del ejido es el 25 de agosto de 1975, y fue publicada en el Diario Oficial de la Federación (DOF) al día siguiente (SRA, 1975). El total de ejidatarios es de 194, de los cuales 167 son varones y 27 son mujeres. Hay 89 avecindados y 48 avecindadas; 70 posesionarios y nueve 
posesionarias. El total de sujetos agrarios es de 410 . El ejido se registró en el Programa de Certificación de Derechos Ejidales y Titulación de Solares Urbanos (Procede) el 5 de diciembre de 1998.

Los asentamientos poblacionales diversos y dispersos de este ejido tienen diferentes fechas de creación. De acuerdo con Lagunas et al. (2008), los primeros asentamientos en el territorio del núcleo agrario datan de 1977. Algunas familias que venían del estado vecino de Baja California, por lo general del valle de San Quintín y Ensenada, que se dedicaban principalmente a la agricultura y la ganadería, se asentaron como nuevos ejidatarios en el pueblo principal de Bonfil. Estas personas provenían por lo regular de estados del Centro, Sur y Noroeste de México. La gran mayoría emigró al Norte del país con la intención de cruzar la frontera con Estados Unidos.

A comienzos de la década de 1980, se incorporaron al sistema ejidal de Bonfil los ranchos y rancherías que se ubicaban por azar dentro de los límites oficiales ejidales: antiguos asentamientos localizados en la sierra de Santa Martha, San Francisco y Mulegé Pueblo. Sus pobladores son en su mayoría familias nativas de la región, descendientes directos de colonizadores extranjeros, sobre todo europeos. Así, el ejido Bonfil es una mezcla de culturas (Lagunas et al., 2008).

Las principales actividades económicas en el ejido son: a) agricultura, con cultivos de dátil de variedad mejorada y siembra de hortalizas, legumbres y frutas; en fechas recientes se cultivan verduras y plantas aromáticas orgánicas; todos los cultivos se riegan con agua que se extrae de acuíferos; b) ganadería bovina y caprina; crianza de aves de corral para autoconsumo; c) ecoturismo, con renta de cabañas; d) pesca, y f) manejo de vida silvestre (Lagunas et al., 2008).

El área comprende porciones de dos subdivisiones del desierto sonorense: Desierto de El Vizcaíno y una porción menor conocida como Costa del Golfo. Casi 9\% de la flora se reconoce como endémica de la región geográfica global, con 496 especies documentadas, aunque se estima que este número representa alrededor de $90 \%$ de la flora total. Respecto a la fauna, predominan los representantes de la vida silvestre de la región biogeográfica neártica (Semarnap, 2000).

\section{EJIDOS CHAMETLA Y EL CENTENARIO, LA PAZ}

La superficie total ejidal de Chametla es de 3621.200171 ha, con 3507.608934 ha parceladas y 113.591237 ha de uso común. La fecha de resolución ejidal fue el 31 de enero de 1940 y se publicó en el DOF el 5 de abril de ese año (Departamento Agrario, 1940). En total, hay 252 sujetos agrarios, de los cuales 109 son ejidatarios, con 92 varones y 17 mujeres; ocho avecindados, una avecindada; 93 posesionarios y 41 posesionarias. El ejido ingresó al Procede el 19 de enero de 1998.

Chametla es el ejido más antiguo de los cuatro. Las ejidatarias que entrevistamos dijeron ser originarias de los estados de Jalisco, Durango, Coahuila y BCS. En la actualidad, forma parte de la mancha urbana de la ciudad de La Paz y tiene 2178 habitantes (INEGI, 2010). Cuenta con servicios urbanos, como calles pavimentadas, banquetas, áreas verdes públicas, zonas recreativas y deportivas, educación básica, centro de salud, servicio postal, energía eléctrica, internet, telefonía, subdelegación y servicio de transporte público, entre otros. A pesar de esto, mantiene un entorno rural y en las partes más alejadas de la infraestructura urbana se conservan amplias áreas forestales y se desarrollan actividades económicas del sector primario —en específico, agropecuarias-.

La superficie total del ejido El Centenario es de 16704.531721 ha, distribuidas en 16403.662798 ha parceladas, 287.195255 ha de asentamientos humanos y 13.673668 ha de uso común. Fue creado el 15 de julio de 1966 y su resolución se publicó en el DOF 
el 4 de agosto de 1966 (Departamento de Asuntos Agrarios y Colonización, 1966). Su padrón está integrado por 1282 sujetos agrarios. En total, hay 190 ejidatarios, con 149 varones y 41 mujeres; 613 avecindados y 434 avecindadas; 30 posesionarios y 14 posesionarias. El Centenario ingresó al Procede el 11 de diciembre de 1998.

En la actualidad, cuenta con 4696 habitantes (INEGI, 2010), la mayoría proveniente de los estados de Michoacán, Oaxaca, Jalisco, Nayarit, Zacatecas, Guerrero, Veracruz, Durango, Sinaloa y BCS. De los cuatro ejidos en estudio, es el que presenta más características urbanas, con educación básica y media superior, centro de salud, clínicas particulares, subdelegación, centros recreativos y deportivos, oficinas del Sistema de Agua Potable Alcantarillado y Saneamiento (SAPA) y del Sistema Nacional para el Desarrollo Integral de la Familia (DIF), y comercios. Tiene también un fraccionamiento y una división catastral urbana que comprende varias colonias bien delimitadas.

Tanto El Centenario como Chametla se encuentran dentro de la mancha urbana de la ciudad capital de La Paz, el primero a $14 \mathrm{~km}$ y el segundo a $7 \mathrm{~km}$ al Oeste, sobre la carretera transpeninsular, a 14 metros sobre el nivel del mar, entre las coordenadas $24^{\circ} 07^{\prime} 97^{\prime \prime} \mathrm{N} / 110^{\circ} 26^{\prime} 53^{\prime \prime} \mathrm{O}$ al Noroeste y $24^{\circ} 07^{\prime} 21^{\prime \prime} \mathrm{N} / 110^{\circ} 25^{\prime} 35^{\prime \prime} \mathrm{O}$ al Sureste. Ambos ejidos poseen terrenos costeros que colindan entre ellos y presentan características ambientales y socioeconómicas similares.

Las actividades económicas predominantes son la agricultura, con cultivos de hortalizas en áreas aledañas, y la ganadería semiextensiva de ganado vacuno y caprino. En las inmediaciones de la ensenada de La Paz, entre ambos ejidos, la zona costera es de uso residencial, con infraestructura industrial, de servicios y recreativa en baja escala. El resto de las zonas adyacentes de litorales de la ensenada es de uso forestal y en la costa es turístico. El cuerpo acuático es de uso recreativo y pesquero.
En las áreas forestales, el tipo de vegetación dominante es el matorral sarcocaule, como en el desierto sonorense. El clima es cálido muy seco - BW (h') hw (e)-, con precipitación invernal superior a 10\% del total anual; el invierno es fresco, pero no se registran heladas (INEGI, 2013; Romero et al., 2006). La precipitación media anual es de $183.6 \mathrm{~mm}$ y la temperatura media anual es de $24^{\circ} \mathrm{C}$ —periodo 1981-2010-.

La vegetación de la línea de costa adyacente, entre el estero Zacatecas y las inmediaciones de la localidad de El Centenario, todavía presenta

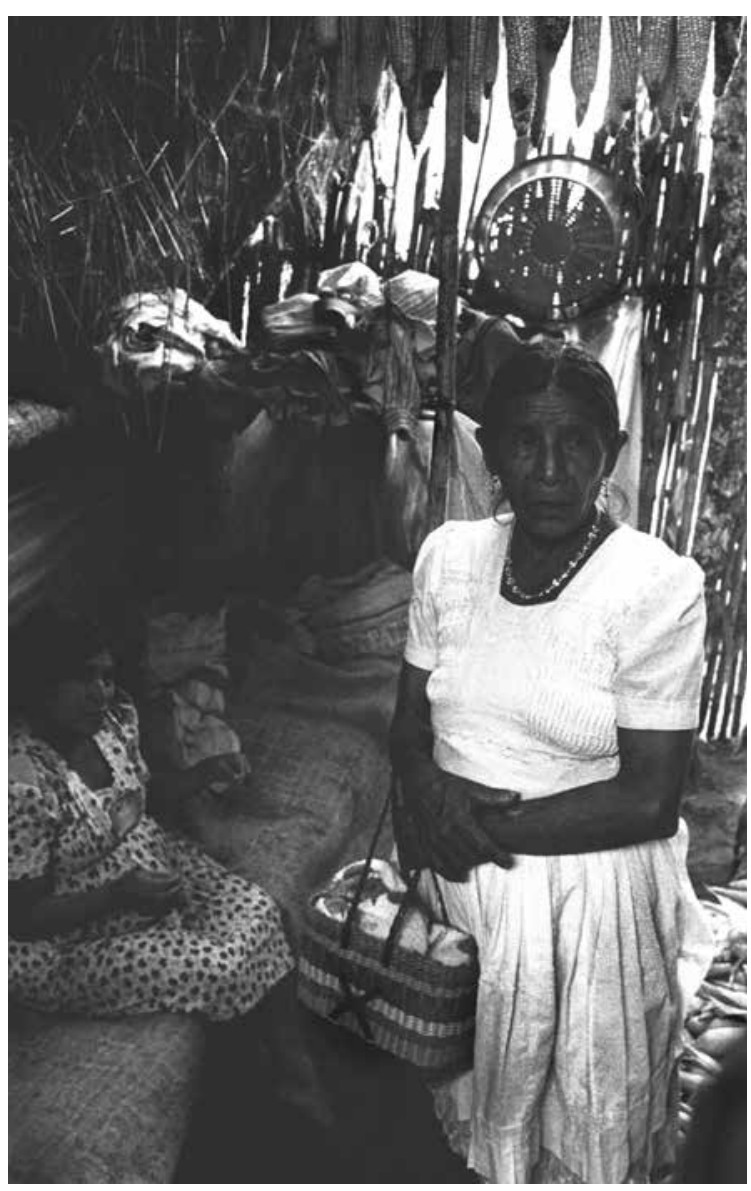

Ricardo Ramírez Arriola • Por respeto y cariño, la gente de las comunidades Ilama a las comadronas "abuelas". San Pedro Pinula, Jalapa, Guatemala, 2000 
una franja de matorral sarcocaule con predominio de cardones — Pachycereus pringlei-, mezquite - Prosopis articulata - , ciruelo - Cyrtocarpa edulis-, torote rojo — Bursera microphylla-, lomboi blanco - Jatropha cinérea-, palo adán -Fouquieria diguettii-, palo brea - Cercidium floridum - , choya -Opuntia cholla-, lomboi rojo -Jatropha cuneata - y pitaya agria — Machaerocereus gummosus-, entre otras (Romero et al., 2006).

Entre las localidades de El Centenario y Chametla predominan las plantas halófitas. Estos sitios están bordeados de planicies de inundación en cuyos márgenes se asienta el tipo de vegetación de matorral sarcocaule. Destacan los parches de manglar (Mendoza, 2007).

\section{EJIDO ALFREDO V. BONFIL, LA PAZ}

El ejido Bonfil cuenta con una superficie total de 42369.380298 ha, de las cuales 2192.523878 ha son parceladas. Los asentamientos humanos ocupan 19.844936 ha y el área de uso común es de 40144.907166 ha. La resolución ejidal data del 2 de septiembre de 1976 y fue publicada en el DOF el 5 de octubre de ese mismo año (SRA, 1976). Este ejido se registró en el Procede el 3 de abril de 1995. El padrón de sujetos agrarios es de 130, con un total de 73 ejidatarios, de los cuales 68 son varones y cinco son mujeres; tiene 40 avecindados y 14 avecindadas; un posesionario y dos posesionarias.

El ejido se sitúa en las coordenadas $24^{\circ} 09^{\prime}$ 5,33”N/103³3'38,76”' O, al Norte del municipio de La Paz, y está comunicado por la carretera San Juan de la Costa hasta el kilómetro 11 y por un camino de terracería de $5 \mathrm{~km}$.

De acuerdo con la descripción etnográfica de Sosa (2013), en 1973 llegaron personas de ciudad Constitución de BCS y otros lugares de los estados de Durango y Guanajuato para empezar a poblar el ejido, aunque la zona estuvo habitada durante años por pequeños ranchos en la serranía y la costa, como es el caso de Salto de Los Reyes, Los Escalones, Rancho Rodríguez, Huerta de Los Reyes, El Cajón de Los Reyes, entre otros.

Empezaron con la siembra de frijol. El agua se obtenía del arroyo cercano y el municipio les trasladaba agua de la ciudad de La Paz, hasta que se hicieron perforaciones locales. Más tarde, se sembraron cítricos —4 ha de mandarina y naranja-, combinados con sandía, melón, tomate, palma y maíz (Sosa, 2013).

Como programa gubernamental para impulsar la ganadería, se desmontaron 1000 ha adyacentes al núcleo poblacional, en las que se introdujo zacate buffel para el ganado de engorda y lechero. Para apoyar la pesca, se proporcionaron cuatro embarcaciones con motores fuera de borda. Como los pobladores no conocían el mar, llegaron personas de La Paz para enseñarles a pescar. Hoy la pesca forma parte fundamental del sustento económico para algunos pobladores que cuentan con una cooperativa pesquera. En 1985, se instaló una ladrillera y esta actividad es parte importante de la manutención de dos familias (Sosa, 2013).

El ejido Bonfil de La Paz tiene 129 habitantes (INEGI, 2010). Cuenta con educación primaria y preescolar, energía eléctrica y agua potable. No hay servicios de salud ni comunicaciones. Las principales actividades económicas actuales son agricultura, ganadería, trabajo de jornalero, aprovechamiento forestal, fruticultura y minería.

De acuerdo con la descripción florística de Sosa (2013), el tipo de vegetación presente es el denominado desierto de Sonora. Por sus características geográficas y climatológicas, predominan diversos tipos de matorral xerófilo. La región pertenece a la zona árida tropical, en la que encontramos terrenos aluviales que contienen matorral micrófilo, de tipo arbustivo con hojas pequeñas, y zonas de matorral sarco-crasicaule. Las cactáceas conforman un grupo importante. 


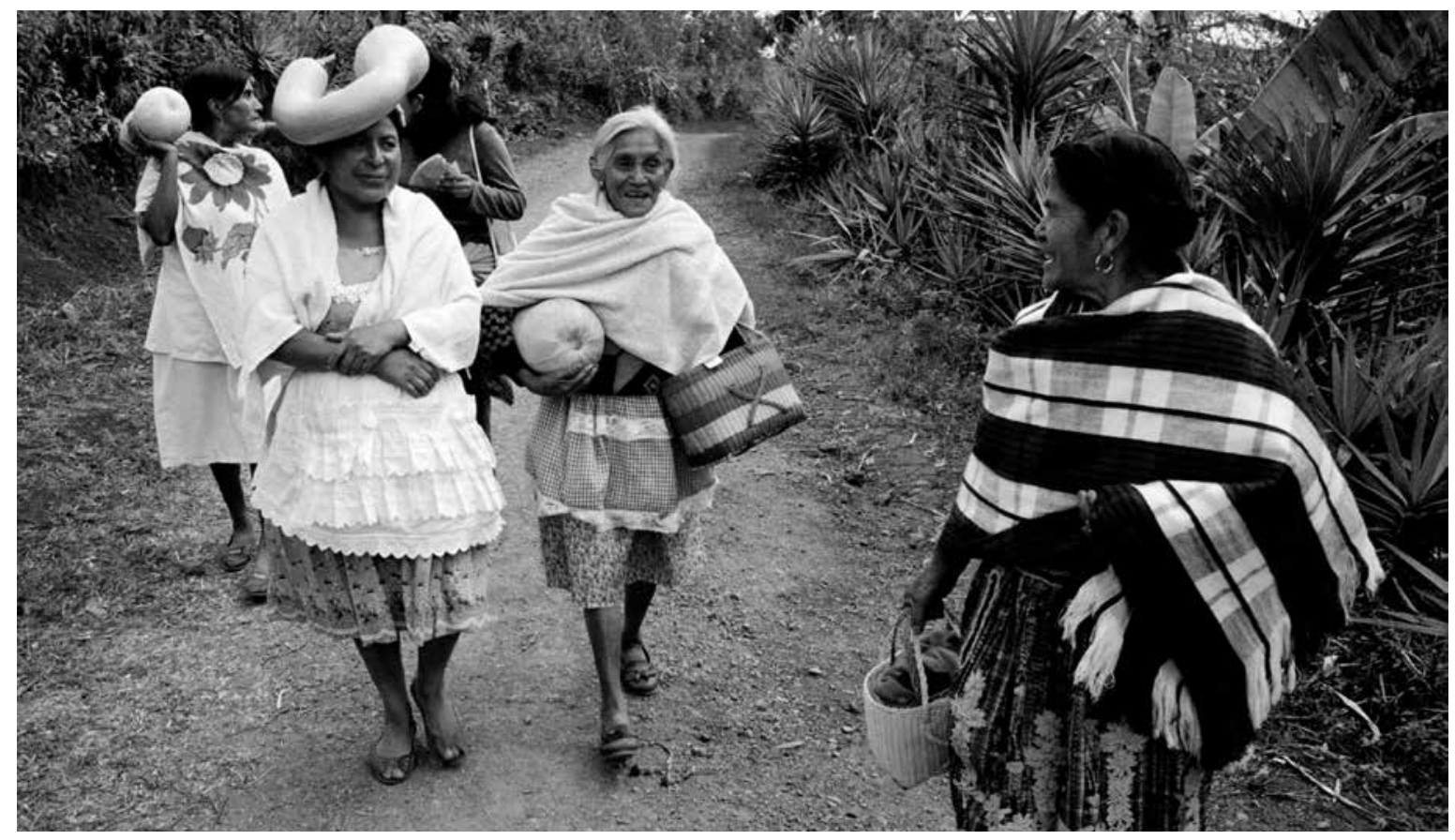

Ricardo Ramirez Arriola • Jalapa, Guatemala.

\section{DISTRIBUCIÓN DE LOS SUJETOS AGRARIOS} EN LOS CUATRO EJIDOS ESTUDIADOS

A la fecha, en los cuatro ejidos están registrados 2079 sujetos agrarios. De este padrón, 566 cuentan con derechos agrarios. La proporción masculina de ejidatarios es de $84 \%$, y de posesionarios, de $75 \%$. Sólo en el conjunto de avecindados, $40 \%$ son mujeres y $60 \%$ hombres, es decir, es un poco más equitativo (véase la figura 1). De los 566 derechos agrarios, sólo 91 corresponden a ejidatarias, es decir, 16\%. Ellas serían los sujetos agrarios con condición de poder y poseedoras de propiedades, con voz y voto en las asambleas y con capacidad para participar en procesos de toma de decisiones respecto al uso del territorio, los recursos ejidales y su forma de gobierno local.

Las cifras de mujeres con derechos agrarios en México son semejantes a las mujeres campesinas con títulos de tierras en Latinoamérica. A principios de 1990, en Honduras, 16\% de los títulos correspondía a las mujeres campesinas (León, 1999); en Bolivia, 17\% en 1994; en Colombia en 1991, en Costa Rica en 1988, en El Salvador en 1991 y en Nicaragua en 1990, la proporción era de 11\% (León, 2006). Nuestros resultados también coinciden con datos observados en otros estudios llevados a cabo en el país: en un análisis de tres ejidos del estado de Veracruz, se encontró una representación femenina de 16\% en dos ejidos, y de 26\% en el tercero (Córdova, 2003).

\section{CARACTERIZACIÓN SOCIOCULTURAL}

\section{DE LAS MUJERES EJIDATARIAS}

La edad promedio de las 31 ejidatarias entrevistadas es de 64 años. También en promedio, tienen cinco hijos. Respecto a la condición escolar y la alfabetización, casi $9 \%$ son analfabetas, 15\% son alfabetas no escolarizadas, 44\% cursó algún año de 

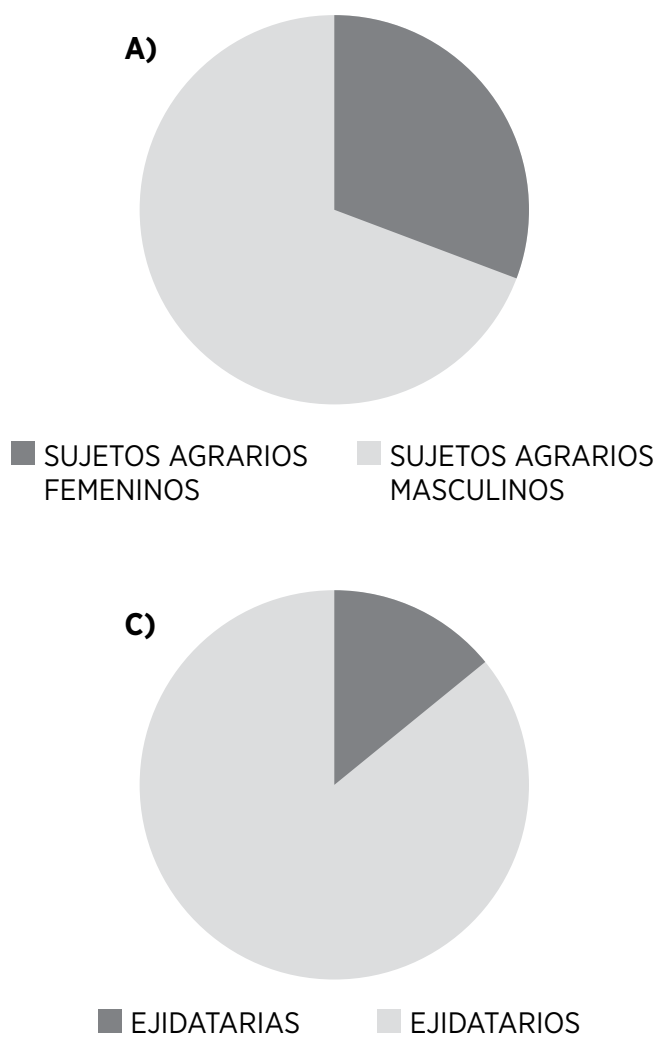

Fuente: Elaboración propia, con base en datos del RAN (2018).

primaria o la terminó, 21\% estudió parte o concluyó la secundaria y 12\% cursó parte o culminó el bachillerato o su equivalente en carrera técnica. La suma de los porcentajes de analfabetas y no escolarizadas es mayor a la de ejidatarias con secundaria o estudios medio superiores.

Las mujeres ejidatarias entrevistadas en el ejido Bonfil, Mulegé, tienen una edad promedio de 62 años, la más joven tiene 41 y la mayor 81 . El promedio de hijos es de 6.4, en un rango que va de dos a 12 hijos. Todas las ejidatarias entrevistadas son alfabetas. Su escolaridad fluctúa entre primaria y preparatoria, 44\% concluyó la primaria. De las ejidatarias
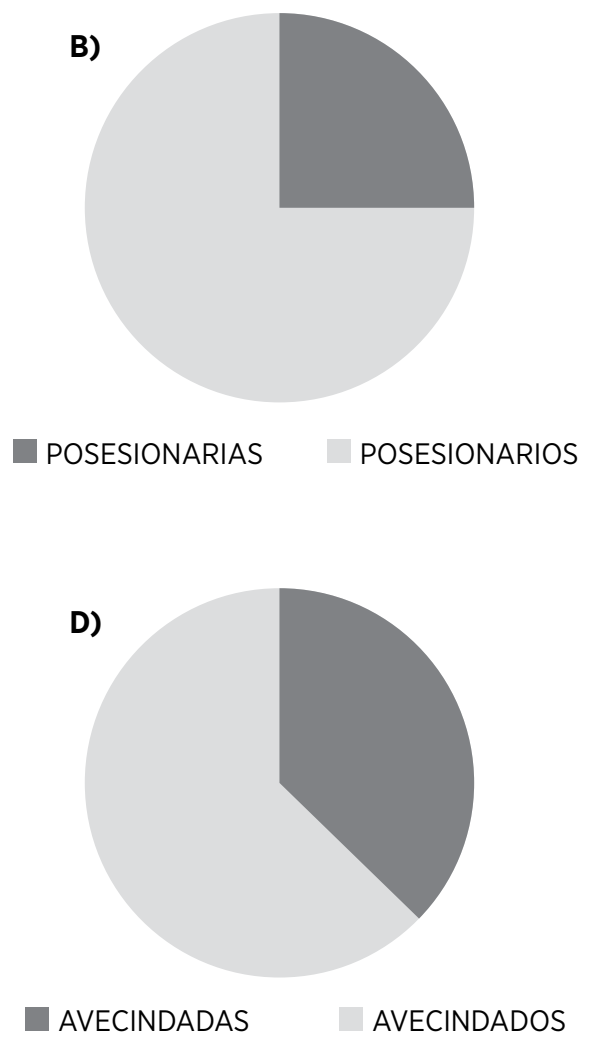

entrevistadas, 78\% es soltera y el resto está casada. Del total, 55\% tiene algún familiar dentro del ejido. La edad promedio del grupo de ejidatarias entrevistadas en el ejido Chametla es de 63.6 años, la más joven tienen $45 \mathrm{y}$ la mayor 86 . El promedio de hijos es de dos. Todas las mujeres ejidatarias entrevistadas son alfabetas y su escolaridad va de primaria a preparatoria, predomina $55 \%$ con primaria terminada o pocos años cursados. Una proporción de 71\% es soltera, el 29\% restante está casada. La mayoría — 80\% - tiene algún familiar dentro del ejido.

Las ejidatarias de El Centenario tienen una edad promedio de 67 años, la más joven tiene 46 y 
la mayor 86. El promedio de hijos es de 4.4, en un rango de uno a 11. La escolaridad de estas mujeres es muy variada, algunas tuvieron oportunidad de estudiar preparatoria o carrera técnica en la ciudad de La Paz, mientras que tres ejidatarias son analfabetas. De las entrevistadas, $50 \%$ cursó la primaria y poco más de 20\% la secundaria. En cuanto al estado civil, $79 \%$ es soltera, y el resto, casada. Una proporción de $42 \%$ tiene algún familiar dentro del ejido.

La información que se obtuvo de las ejidatarias del ejido Bonfil, La Paz, fue mínima pues sólo cinco mujeres tienen derecho agrario y sólo una vive en el núcleo ejidal. De ella se obtuvo información general de sus compañeras. Todas las ejidatarias de Bonfil recibieron su derecho agrario por herencia, 75\% por viudez y $25 \%$ por su padre. La edad promedio es de 54 años, $66.6 \%$ es soltera y el resto es casada. La ejidataria entrevistada es alfabeta, pero no escolarizada.

\section{PATRONES Y PROCESOS DE ACCESO A LA TIERRA \\ Y AL DERECHO AGRARIO DE LAS EJIDATARIAS}

La adquisición de sus derechos agrarios es por herencia en $88 \%$ de los casos y por iniciativa personal en $12 \%$ solamente. De los derechos agrarios heredados, una mitad fue por parentesco y la otra por viudez. A la misma conclusión llegan estudios tanto nacionales (Cuaquentzi, 2007; Almeida, 2009; 2012), como latinoamericanos (León, 1999; Deere y León, 2005; Almeida, 2009).

Sólo en dos de los cuatro ejidos hay mujeres que adquirieron sus derechos agrarios por iniciativa propia. Incluso en estos casos es notorio que no los obtuvieran a título personal, pues tuvieron que manifestar otras condiciones. Por ejemplo, las ejidatarias de Bonfil, Mulegé, eran madres solteras, es decir, mujer-madre; en el ejido El Centenario, algunas desempeñaron trabajos agrícolas durante años — una de ellas casi 15 , y otras, más de cinco-, y demostraron que vivían y dependían de la tierra al mismo tiempo que emprendían una verdadera lucha para obtener sus derechos agrarios. La herencia por parentesco tampoco es neutral. En más de un ejido se repitió la historia de que la hija o sobrina heredaba porque no había otra opción o porque el heredero original, que pudo haber sido su hermano, no estaba interesado en el derecho agrario y se lo traspasó. Estas condiciones se exponen en otros estudios realizados en diversos ejidos del país (Almeida, 2009; 2012). Es claro que para las mujeres entrevistadas en estos cuatro ejidos la Reforma Agraria y la Ley Agraria no las favorecieron, pues el proceso de reparto no las benefició de manera directa.

\section{LAS PREFERENCIAS DE HERENCIA DEL DERECHO EJIDAL POR PARTE DE LAS EJIDATARIAS}

Acerca de las preferencias de herencia del derecho agrario en el análisis global, 9.5\% de las ejidatarias declaró que favorece a los hijos varones y $24 \%$ a las hijas, para $53 \%$ es indistinto, mientras que $9.5 \%$ no ha decidido y $4 \%$ prefiere no heredar a sus descendientes.

Los resultados de nuestro análisis sobre las prácticas de herencia son similares a los que arrojan otros estudios: la herencia es de preferencia masculina (Córdova, 2003; Del Rey, 2005; Almeida, 2012). Los trabajos revisados sobre el tema (Vázquez, 2001; Córdova, 2003) consideran que estas prácticas socioculturales, que incluyen redes de parentesco, corresponden a lo propuesto por Robichaux (2002) como modelo o sistema familiar mesoamericano, en el cual, con base en la herencia y la residencia, la herencia de bienes es patrilineal y la residencia posmarital es virilocal. Es decir, se prefiere la herencia masculina. Las tierras, los derechos agrarios y las casas se heredan a los hijos varones, que poseen más libertad de movimiento y decisión. Por lo general, las hijas se casan y se mudan a casa de sus suegros. Van sin herencia porque se entiende que el varón con el que se casan tendrá la suya y la compartirá, según las 
pautas del "buen patriarca" a las que Deer (1986) y Vizcarra (2001) hacen alusión.

Respecto a la preferencia de herencia de su derecho ejidal, las ejidatarias del ejido Bonfil, Mulegé, respondieron lo siguiente: $22.2 \%$ a una hija, $11.1 \%$ a un hijo, para $66.7 \%$ es indistinto. En Chametla, las ejidatarias prefieren dejar el derecho agrario a sus hijas en una proporción de 50\%, mientras 25\% mencionó a sus hijos varones, para el resto es indistinto. De las ejidatarias de El Centenario, 14\% dijo que le heredaría a una hija, 29\% aún no ha decidido y $57 \%$ respondió que le resultaba indistinto.

\section{PERCEPCIÓN SOBRE DISCRIMINACIÓN EJIDAL}

Sobre la percepción de discriminación hacia las mujeres en el entorno ejidal, 59\% de las ejidatarias entrevistadas en los cuatro ejidos consideró que sí existe y 36\% declaró haberla sentido en su propia persona. Entre los tipos de discriminación que mencionan se reconocen racismo, sexismo, clasismo e indiferencia - violencia-.

En el ejido Bonfil, Mulegé, 66\% de las entrevistadas considera que hay discriminación dentro del ejido. La misma proporción declaró no haberla sentido nunca en persona; 34\% mencionó haber sentido algún tipo de discriminación en algún momento de su vida. Las entrevistadas en este ejido coincidían en que la discriminación —en las asambleas, algunas veces - se dirige tanto hacia ellas como hacia los varones ejidatarios cuando disienten de las opiniones de las autoridades ejidales:

Existe discriminación de manera indistinta tanto para hombres como para mujeres (entrevista con ejidataria 31, ejido Bonfil, Mulegé, marzo de 2016).

El comisariado no atiende mis peticiones y me ignora cuando hablo (entrevista con ejidataria 29, ejido Bonfil, Mulegé, marzo de 2016).
Existe indiferencia (entrevista con ejidataria 31, ejido Bonfil, Mulegé, marzo de 2016).

Castigan a los ejidatarios anulando sus derechos por periodos, a nombre de la asamblea, si se defienden o hablan contrario a lo planteado por el comisariado (entrevista con ejidataria 31, ejido Bonfil, Mulegé, marzo de 2016).

De las ejidatarias de Chametla, 60\% de las entrevistadas considera que sí existe discriminación hacia las mujeres; $50 \%$ declaró haber sentido discriminación alguna vez en carne propia. Sin embargo, ninguna enunció alguna situación o ejemplo en el que hubiera padecido algún tipo de discriminación.

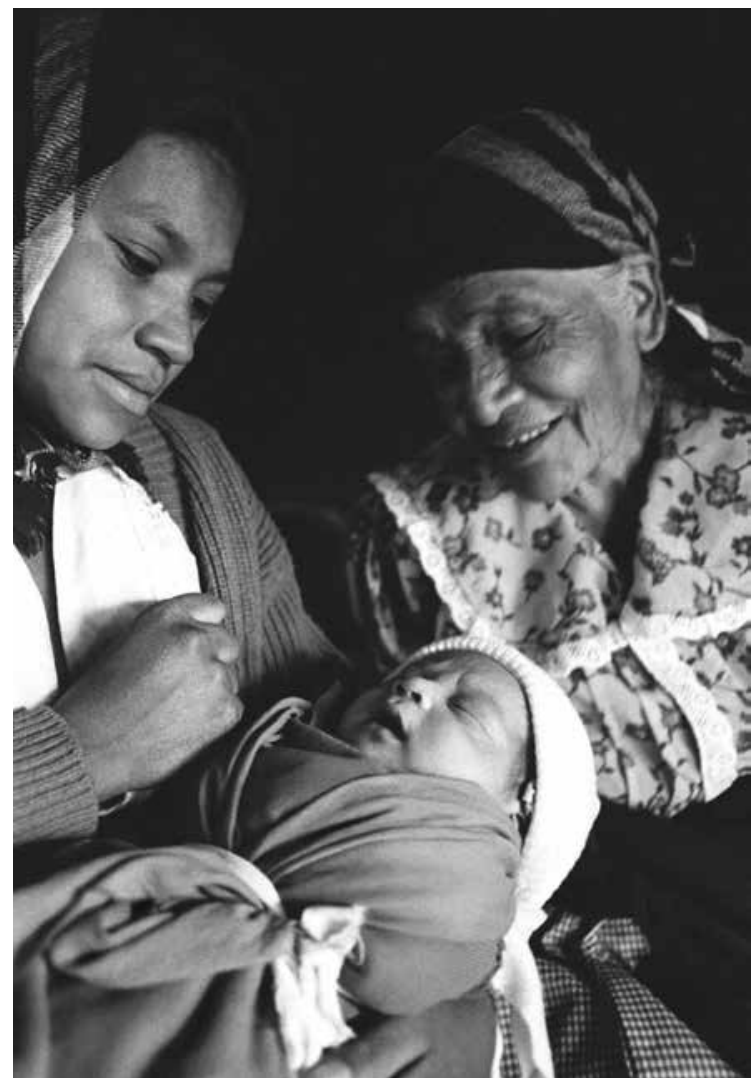

RICARDO RAmírez ARRIOLA • La mayoría de las comadronas heredó el oficio de sus abuelas o madres. San Pedro Pinula, Jalapa, Guatemala, 2000. 
En el ejido El Centenario, 58.3\% de las entrevistadas consideran que existe discriminación dentro del ejido y $54.5 \%$ declaró no haberla sentido nunca. El resto consideró que había sentido algún tipo de discriminación, como se plasma en estas frases:

No me tomaban en cuenta cuando estaba exigiendo el reconocimiento del derecho ejidal que mi esposo me había dejado de herencia (entrevista con ejidataria 13, ejido El Centenario, La Paz, junio de 2016).

Por ejemplo, cuando alguien quiere comprar una res, es muy difícil que se pueda hacer la venta. [He sentido] discriminación al querer poner en venta un terreno, la discriminación al establecer un precio (entrevista con ejidataria 6, ejido El Centenario, La Paz, junio de 2016).

\section{PARTICIPACIÓN POLÍTICA DE LAS MUJERES EJIDATARIAS EN EL ENTORNO EJIDAL}

Respecto a la participación pública ejidal, 28\% de todas las ejidatarias entrevistadas ha incursionado en este tipo de actividades. El resto nunca lo ha hecho. A 86\% le gusta que las mujeres participen en cargos públicos y $66 \%$ considera que tienen menos tiempo que los ejidatarios para participar en cargos públicos y políticos.

Las ejidatarias del ejido Bonfil, Mulegé, no pretenden participar en cuestiones públicas y políticas del ejido. Cuando preguntamos si les gustaría participar en algún cargo público dentro del ejido, una de ellas contestó: "no, yo no sé ni hablar, ni nada" (entrevista con ejidataria 31, ejido Bonfil, Mulegé, marzo de 2016). Todas se han dedicado principalmente al hogar. Todas tuvieron o tienen actividades socioeconómicas fuera de casa, pero de manera restringida. Estas mujeres reconocen el hogar como su principal actividad.

Sobre la participación política, la mayoría de las ejidatarias de Bonfil nunca ha tenido un cargo en el ejido; sólo alrededor de 20\% ha ostentado algún cargo político, como secretarias, tesoreras o suplentes en el Comisariado Ejidal. Casi todas — 90\%— mencionaron que les agrada que las mujeres ocupen cargos políticos. Todas coincidieron en que no tienen tiempo para atender una función pública o política.

En el ejido El Centenario hay mujeres ejidatarias con una carrera política de 20 a 30 años o más. Las mujeres que han participado en cargos públicos han desempeñado varias funciones no comunes para la mayoría de las mujeres en el ámbito rural. En este ejido ha habido una diputada federal, diputadas en el congreso local estatal, regidoras, subdelegadas, todas ligadas al Partido Revolucionario Institucional (PRI), y dentro del Comisariado Ejidal han ostentado los cargos de presidentas, tesoreras y secretarias.

Aproximadamente 31\% de las mujeres ejidatarias ha ostentado algún cargo político y $92 \%$ mencionó que les agrada que las mujeres lo hagan. Hubo coincidencia de $56 \%$ de las ejidatarias en no tener tiempo para atender una función pública o política.

\section{Conclusiones}

La representación de ejidatarias en los ejidos analizados es mínima - 16\%- Algo similar se observa en el Censo ejidal 2007 (INEGI, 2007), en el que BCS registró $16.6 \%$ de mujeres ejidatarias en el total estatal de derechos agrarios. Esta cantidad está por debajo de lo observado en el país — 19.8\%—, en el rubro de representación femenina en el padrón de ejidatarios.

En este sentido, podrían implementarse algunas acciones afirmativas para propiciar mayor igualdad en cuanto a derechos sobre la propiedad de la tierra y equidad respecto a la tenencia a favor de las mujeres rurales mexicanas. Los certificados de derechos agrarios podrían reelaborarse a nombre de ambos cónyuges — matrimonios y parejas 


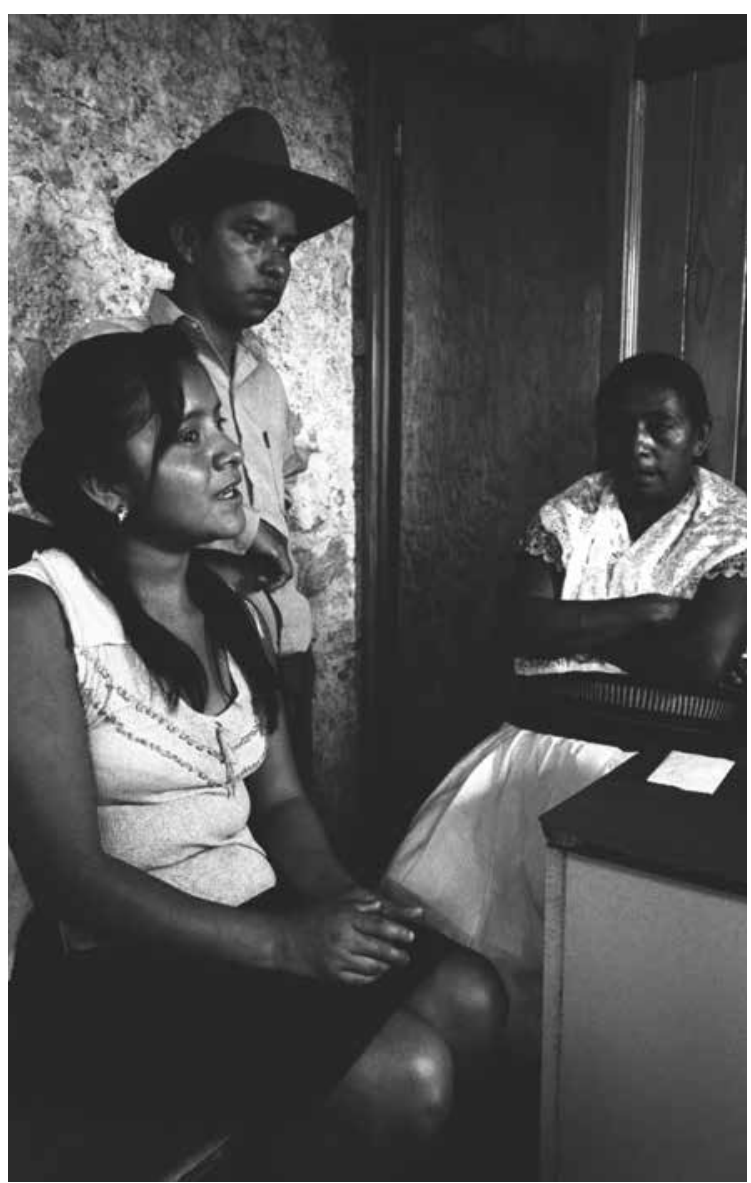

Ricardo Ramírez Arriola • Instituto Mexicano del Seguro Social en la Sierra Norte de Puebla, México.

de hecho- como copropietarios, con la especificación de que todo nuevo derecho agrario será un bien mancomunado, compartido a partes iguales entre los miembros de una pareja. Estas recomendaciones se aplican también a los casos de las parejas del mismo sexo que hereden o posean un derecho agrario.

Respecto a la participación política en el ejido, nuestros datos coinciden con otro estudio en el que se analizan tres ejidos (Córdova, 2003), y justo en el que hay más porcentaje de ejidatarias también ha habido participación como comisariadas en la mesa directiva del ejido al que pertenecen.
Hacen falta estudios etnográficos que ubiquen las diferencias culturales entre los ejidos y comunidades, que utilicen en primer término la clasificación de sistemas socioculturales rurales de González (1989), quien considera rasgos culturales más allá de la categoría de lengua indígena. Como lo plantea Good (2013), es importante que se incluyan las categorías en la construcción sociocultural de género. En un plano amplio, México posee una gama de diversidad cultural cuyas diferencias deben identificarse con claridad para no caer en las categorías dicotómicas clásicas de las ciencias sociales occidentales (Good, 2013).

Como lo han planteado otras investigaciones de largo aliento, con más de 30 años de estudios sobre el tema (León y Deere, 1978; Deere y León, 2001, 2005; León, 2006; 2011; Deere, 2012), la cuestión cultural es determinante para la situación de las mujeres rurales en Latinoamérica. En México en particular, los patrones culturales de acceso a la tierra, las costumbres sobre la herencia, y en general, el papel de la mujer campesina en la sociedad occidental, patriarcal y capitalista propician la situación de desigualdad que prevalece en el campo. Se considera recomendable que se implementen programas y acciones de concientización y sensibilización que promuevan los derechos de propiedad y la igualdad entre las ejidatarias, posesionarias y avecindadas de los ejidos, para que incrementen sus capacidades para exigir sus derechos y administrar su patrimonio, así como actividades de empoderamiento rural e indígena femenino a favor de la tierra para las mujeres campesinas.

Es urgente que se instrumenten disposiciones estructurales para la aplicación de medidas afirmativas o acciones correctivas, como promover beneficios temporales que se utilicen para eliminar o disminuir situaciones de discriminación (Castro, Urrea y Viáfara, 2009; Alfaro, Aguilar y Badilla, 1999: 26), así como para propiciar una condición de mayor igualdad y equidad entre los hombres y mujeres rurales en México. D 


\section{Bibliografía}

Alfaro, María Cecilia, Lorena Aguilar y Ana Elena Badilla, 1999, Develando el género. Elementos conceptuales básicos para entender la equidad, Unión Mundial para la Naturaleza/Fundación Arias para la Paz y el Progreso Humano, San José.

Almeida, Elsa, 2009, “Ejidatarias, posesionarias, avecindadas. Mujeres frente a sus derechos de propiedad en tierras ejidales de México”, en Estudios Agrarios, vol. 18, núm. 52, pp. 13-57.

__ 2012, "Herencia y donación. Prácticas intrafamiliares de transmisión de la tierra: el caso de un ejido veracruzano", en Cuicuilco, vol. 19, núm. 54, pp. 55-79.

Castillo Hernández, Rosalva Aída, 2001, "Entre el etnocentrismo feminista y el esencialismo étnico. Las mujeres indígenas y sus demandas de género”, en Debate Feminista, núm. 24, pp. 206-229.

Castro Heredia, Javier Andrés, Fernando Urrea Giraldo y Carlos Augusto Viáfara López, 2009, "Un breve acercamiento a las políticas de Acción Afirmativa: orígenes, aplicación y experiencia para grupos étnico-raciales en Colombia y Cali”, en Sociedad y Economía, núm. 16, pp. 159-170.

Chávez Frías, Hugo, 2001, Ley de tierras y desarrollo agrario, en Gaceta Oficial de la República Bolivariana de Venezuela, núm. 37323,13 de noviembre. Disponible en línea: <http://www.ventanalegal.com/leyes/ley_tierras.html>.

Córdova Plaza, Rosío, 2003, "Acceso de las mujeres a la tierra y patrones de herencia en tres comunidades ejidales del centro de Veracruz", en Relaciones. Estudios de Historia y Sociedad, vol. 24, núm. 93, pp. 179-212. Disponible en línea: <http://www.redalyc.org/articulo. oa?id=13709309>. Consultado el 14 de marzo de 2016.

Cuaquentzi Pineda, Fabiola, 2007, "Mujeres y parcela: acceso a la tenencia de la tierra y el agua en el ejido de Mixquiahuala, Hidalgo", en Estudios Agrarios, núm. 34, pp. 95-119.

Deere, Carmen Diana, 1986, "La mujer rural y la política estatal: la experiencia latinoamericana y caribeña de reforma agraria”, en Magdalena de León y Carmen Diana Deere (eds.), La mujer y la política agraria en América Latina, Siglo XXI Editores, México, pp. 187-208

2012, “Tierra y la autonomía económica de la mujer rural: avances y desafíos para la investigación”, en Anthropológicas, vol. 23, núm. 1, pp. 12-66.

Deere, Carmen Diana y Magdalena León, 2002, Género, propiedad y empoderamiento: tierra, Estado y mercado en América Latina, Tercer Mundo Editores/Universidad Nacional de Colombia-Facultad de Ciencias Humanas, Bogotá.

—_, 2004, "Revertir la reforma agraria con exclusión de género: lecciones a partir de América Latina”, en El Otro Derecho, núms. 31-32, pp. 181-220.

_ _ 2005, "La brecha de género en la propiedad de la tierra en América Latina”, en Estudios Sociológicos, vol. 23, núm. 68, pp. 23-68.

Departamento Agrario, 1940, "Resolución en el expediente de dotación de ejidos al poblado Chametla, Territorio Sur de la Baja California”, en Diario Oficial de la Federación, 5 de abril. Disponible en línea: <http://www.dof.gob.mx/nota_to_imagen_fs.php?codnota=4518894\&f echa=05/04/1940\&cod_diario=192496>.

Departamento de Asuntos Agrarios y Colonización, 1966, "Resolución sobre la creación de un nuevo centro de población agrícola que se denominará El Centenario en La Paz, B. Cfa.”, en Diario Oficial de la Federación, 4 de agosto. Disponible en línea: <http://www.dof.gob. mx/nota_to_imagen_fs.php?codnota=4682363\&fecha=04/08/1966\&cod_diario=201757>.

Facio, Alda, 2002, "Con los lentes de género se ve otra justicia”, en El Otro Derecho, núm. 28, pp. 85-102.

Gallart Nocetti, María Antonieta, Alejandro Ibarra, Arnulfo Embriz, Arturo Sánchez Zavala, Citlalli Durán, Filiberto Flores, José Luis Campos, José Luis Bonilla, José Luis Krafft, Ludka de Gortari, Mónica Oliva, Octavio Pérez Nieto, Óscar Fernández Piccolo, Rubén Herrera y Sergio Ortiz, 1999, "El Registro Agrario Nacional”, en Estudios Agrarios, núm. 12, pp. 197-224.

González, Luis, 1989, "Gente del campo. Entrevista con Enrique Krauze”, en Vuelta, núm. 151, pp. 22-29.

Good Eshelman, Catharine, 2013, “Formas de organización familiar náhuatl y sus implicaciones teóricas”, en La Ventana, vol. 4, núm. 37, pp. 9-40. Instituto Nacional de Estadística y Geografía (INEGI), 2007, Censo ejida/ 2007, Instituto Nacional de Estadística y Geografía, México. Disponible en línea: <http://www.inegi.org.mx/est/contenidos/proyectos/accesomicrodatos/cae2007/default.aspx>.

, 2010, Censo de Población y Vivienda 2010. Principales resultados por localidad, Instituto Nacional de Estadística y Geografía, México. Disponible en línea: <http://www3.inegi.org.mx/sistemas/scitel/Default?ev=5>.

,2013, Anuario estadístico de Baja California Sur 2012, Instituto Nacional de Estadística y Geografía/Gobierno del Estado de Baja California Sur, México. 
Lagunas Vázquez, Magdalena, Luis Felipe Beltrán Morales, José Urciaga García y Alfredo Ortega Rubio, 2008, "Evaluación rural participativa: uso de los recursos naturales en la reserva de la biosfera El Vizcaíno, Bcs, México", en Economía, Sociedad y Territorio, vol. 8, núm. 26, pp. 451-476.

Lamas, Marta (comp.), 1996, El género. La construcción cultural de la diferencia sexual, Universidad Nacional Autónoma de México-Programa Universitario de Estudios de Género, México.

León, Magdalena, 1999, Movimiento social de mujeres y paradojas de América Latina, Universidad Internacional de Andalucía, Sevilla.

—_, 2006, "Neutralidad de género y políticas públicas en las reformas agrarias de América Latina”, en Nómadas, vol. 24, pp. 44-52.

__ 2011, "La desigualdad de género en la propiedad de la tierra en América Latina”, en Christine Verschuur (dir.), Du grain à moudre. Genre, développement rural et alimentation, Direction du développement et de la coopération/Institut universitaire d'études et de développement, Ginebra, pp. 189-207.

León, Magdalena y Carmen Diana Deere, 1978, “Estudio de la mujer rural y el desarrollo del capitalismo en el agro colombiano”, en Demografía y Economía, vol. 12, núm. 1, pp. 4-36.

Marcos, Sylvia, 2014, "Feminismos en camino descolonial”, en Márgara Millán (coord.), Más allá del feminismo: caminos para andar, Red de Feminismos Descoloniales, México, pp. 15-34.

Mendoza Salgado, Renato A., 2007, "Ficha informativa de los humedales de Ramsar (FIR)". Disponible en línea: <http://ramsar.conanp.gob. mx/docs/sitios/FIR_RAMSAR/Baja_California_Sur/El\%20Mogote-Ensenada\%20de\%20La\%20Paz/Mexico\%20El\%20Mogote\%20 Ensenada\%20de\%20La\%20Paz\%20RIS\%20S\%202008.pdf>.

Ordenamiento Ecológico Territorial para la Reserva El Vizcaíno (OET), 2003, Conanp- RBV-Cibnor, documento técnico, Baja California Sur.

Pérez-Ruiz, Maya Lorena (coord.), 2004, Tejiendo historias. Tierra, género y poder en Chiapas, Instituto Nacional de Antropología e Historia, México.

Procuraduría Agraria (PA), 2011, Estadísticas agrarias 2011, Procuraduría Agraria-Dirección General de Estudios y Publicaciones, México.

Registro Agrario Nacional (RAN), 2018, Módulo de Consultas de Sistema Integral de Modernización Catastral y Registral. Disponible en línea: <http://consultasimcr.ran.gob.mx/consultassujetoagrario.aspx>

Rey Poveda, Luis Alberto del, 2005, "El nuevo marco de relaciones intergeneracionales en las familias ejidales: migración y herencia en el sur de Veracruz", en Estudios Agrarios, núm. 28, pp. 151-193.

Reyes Ramos, María Eugenia, 2006, "Mujeres y tierra en Chiapas”, en El Cotidiano, vol. 21, núm. 139, pp. 20-30.

Robichaux, David, 2002, "El sistema familiar mesoamericano y sus consecuencias demográficas", en Papeles de Población, vol. 8, núm. 32, pp. 59-95.

Rocha Sánchez, Tania Esmeralda y Rolando Díaz Loving, 2011, Identidades de género, Trillas, México.

Rojas, Rosa (ed.), 1995, Chiapas y las mujeres ¿qué?, t. II, La Correa Feminista/Centro de Investigación, Capacitación y Apoyo a la Mujer (Del Dicho al Hecho), México.

Romero López, Blanca Estela, José Luis León de la Luz, Gustavo de la Cruz Agüero y José Juan Pérez Navarro, 2006, "Estructura y composición de la vegetación de la barra costera El Mogote, Baja California Sur, México”, en Boletín de la Sociedad Botánica de México, núm. 79, pp. 21-32.

Secretaría de la Reforma Agraria (SRA), 1975, "Resolución sobre la creación de un nuevo centro de población ejidal que se denominará Lic. Alfredo V. Bonfil, y quedará ubicado en el municipio de Mulegé, Baja California Sur", en Diario Oficial de la Federación, 29 de agosto. Disponible en línea: <http://dof.gob.mx/nota_detalle.php?codigo=4809957\&fecha=29/08/1975>.

- 1976, "Resolución sobre la creación de un nuevo centro de población ejidal que se denominará Alfredo Vladimir Bonfil, y quedará ubicado en el Municipio de La Paz, B. C.", en Diario Oficial de la Federación, 5 de octubre. Disponible en línea: <http://www.dof.gob.mx/ nota_detalle.php?codigo $=4851907 \&$ fecha $=05 / 10 / 1976>$.

, 1992, Ley agraria, en Diario Oficial de la Federación, 26 de febrero. Disponible en línea: <http://www.diputados.gob.mx/LeyesBiblio/ ref/lagra/LAgra_orig_26feb92_ima.pdf>.

Secretaría de Medio Ambiente, Recursos Naturales y Pesca (Semarnap), 2000, Programa de manejo Reserva de la Biosfera El Vizcaíno, México, Instituto Nacional de Ecología, México.

Sosa y Silva, Adán Gerardo, 2013, Análisis del potencial para la práctica del turismo alternativo integral en la zona del ejido Alfredo Vladimir Bonfil, La Paz, Baja California Sur, México, tesis de licenciatura en turismo alternativo, Universidad Autónoma de Baja California SurDepartamento de Economía, La Paz.

Speed, Shannon, 2004, "Lucha por la tierra, globalización e identidad: la etnohistoria y el etnopresente de Nicolás Ruiz", en Maya Lorena Pérez-Ruiz (coord.), Tejiendo historias. Tierra, género y poder en Chiapas, Instituto Nacional de Antropología e Historia, México. 
Vázquez García, Verónica, 2001, “Género y tenencia de la tierra en el ejido mexicano: ¿̇la costumbre o la ley del Estado?”, en Estudios Agrarios, núm. 18, pp. 117-146.

Vizcarra Bordi, Ivonne, 2001, "... Y la lucha sigue entre sombreros y rebozos. Historia de una tierra de subsistencia marginal mazahua”, en Estudios Agrarios, núm. 18, pp. 9-73.

Warman, Arturo, 1978, “Frente a la crisis, ¿̇política agraria o política agrícola?”, en Comercio Exterior, vol. 28, núm. 6, pp. 681-687.

__ 1985, "Notas para una redefinición de la comunidad agraria”, en Revista Mexicana de Sociología, vol. 47, núm. 3, pp. 5-20. , 1996, "La reforma al artículo 27 constitucional”, en Estudios Agrarios, núm. 2, pp. 9-25.

, 2003, "La reforma agraria mexicana: una visión de largo plazo", en Land Reform, Land Settlement and Cooperatives. Reforma agraria, colonización y cooperativas, vol. 2, Food and Agriculture Organization, pp. 85-94.

\section{Cartografía}

Instituto Nacional de Estadística y Geografía (INEGI), 2012, "Carta de uso del suelo y vegetación”, escala 1: 250,000, serie IV, La Paz G12-10-11, en Conociendo México, Instituto Nacional de Estadística y Geografía, Aguascalientes.

\section{Entrevistas}

Ejidataria 29, ejido Bonfil, Mulegé, marzo de 2016.

Ejidataria 31, ejido Bonfil, Mulegé, marzo de 2016.

Ejidataria 6, ejido El Centenario, La Paz, junio de 2016.

Ejidataria 13, ejido El Centenario, La Paz, junio de 2016.

Ejido Bonfil, La Paz, Baja California Sur, julio de 2016: Ofelia.

Ejido Bonfil, Mulegé, Baja California Sur, febrero y marzo de 2016: María Esther, Olivia, Magdalena, Gloria, Margarita, Rosario, Concepción, Guadalupe, Blasa.

Ejido Centenario, La Paz, Baja California Sur, junio y julio de 2016: Consuelo, Inés, Esthela, Francisca, Nicolasa, María, Matilde, Ofelia, María, María, Martina, Sara, María, Julia.

Ejido Chametla, La Paz, Baja California Sur, junio y julio de 2016: Bertha, María, Antonia, María, Guadalupe, Lourdes, Elvia. 